\title{
¿CÓMO SIGNIFICA EL DOCENTE SU ENTORNO?
}

\author{
Linda Aglae Hinojosa Morán*
}

\section{RESUMEN}

El presente artículo pretende mostrar los aspectos que los actores educativos ponen en juego para significar su entorno, considerando los diversos factores que intervienen en el proceso. Lo anterior con dos intenciones, la primera de ellas establecer que la investigación educativa es un proceso que no puede ser abordado de una manera lineal, o con la aplicación de fórmulas específicas, debido a que cada espacio educativo representa un espacio social que se construye a partir de las interacciones que se dan entre las subjetividades de los sujetos que lo componen. La segunda intención es: difuminar la idea naturalista y determinista que se le adjudican a las estructuras sociales, lo que posibilita un actuar más crítico y reflexiva en los diferentes campos sociales, incluyendo el educativo.

\section{ABSTRACT}

The following item intend to show the aspects that the educational participants get hold of to describe their environment, bearing in mind the various factors that take part in the process. The two reasons for this are, first, to establish that educational research is a process and not a one course process to be seized by applying specific formulas, since each educational space represents a social space which is built and rebuilt starting from the interactions that occur among the individuality of the subjects forming it. The second reason is to fade away the naturalist and fatalist ideas, which are considered as part of the social structures, which makes it possible to act more critically and reflectively in different social fields, including the educational one.

Palabras clave: Doxa, interpretación, comprensión, subjetividad.

Keywords: Doxa, interpretation, comprehension, subjectivity.

Estudiante de Maestría en Educación de la Universidad Pedagógica Nacional. Correo electrónico: aglaelin@hotmail.com.

Recibido 20-III-2009 * Aceptado 28-V-2009 * Corregido -VI-2009

\section{INTRODUCCIÓN}


Durante los últimos años hemos sido testigos del gran interés que las dinámicas escolares han despertado en todo el mundo. La búsqueda de lo que muchos llaman educación de calidad ha hecho que los actores educativos se sitúen en el ojo del huracán, por lo que numerosas son las investigaciones que pretenden develar los aspectos que determinan, movilizan y estructuran las interrelaciones de los sujetos que dan vida a las instituciones educativas.

Los discursos sobre la mejora educativa son publicitados a lo largo y ancho de todo el globo y se depositan en la educación las aspiraciones utópicas de todo un país, un continente, en general de todo un planeta. Por esta razón muchas de las personas que hablan de educación lo hacen considerando que por el hecho de utilizar la misma palabra atienden al mismo significado, sin embargo al igual que cualquier símbolo, la palabra educación adquiere múltiples significados en función de la persona que la utilice y el contexto en que lo haga; es decir, desde el momento en que es enunciada, adquiere una postura ideológica inevitable, adjudicada por la realidad social de su producción. Lo anterior desecha de manera obvia la supuesta neutralidad que durante muchos años se le otorgó a la educación y por añadidura a los docentes, quienes fueron considerados como la maquinaria que podía producir una sociedad educada y disciplinada.

No obstante, al paso de los años han surgido nuevas corrientes de estudio que tratan de analizar la práctica educativa, considerando a sus partícipes como actores sociales que al igual que el resto de las personas en este mundo construyen a lo largo de su vida una forma particular de comprender e interactuar en su entorno, de esta manera el peso que durante algún tiempo se le dio al estudio de la profesión docente como ente alejado de la subjetividad del individuo se ha fracturado, perdiendo validez frente a teorías que asumen que la profesión no puede ser considerada como la totalidad de un sujeto, sino como un componente más que lo constituye y que se conforma a través de él.

En este entendido, si se pretenden comprender las prácticas educativas que se realizan dentro de las aulas, es preciso reconocer que su producción no se limita al espacio físico donde se observan, sino que se relacionan con las historias de vida de los sujetos que las protagonizan y los contextos en los que se ubican. El énfasis de la investigación sobre la práctica educativa ya no se coloca en "cómo deberían ser", pues esto sería querer adaptar las acciones y formas de pensar de los sujetos que las protagonizan a un molde rígido. Lo anterior no generaría ningún análisis reflexivo, dado que sólo nos aportaría una mera clasificación de características. Por el contrario al hablar de comprensión, entramos dentro de un campo mucho más flexible y de múltiples posibilidades que nos permite no sólo ver lo que el otro ve, sino reconocer el significado que le da al objeto o suceso 
observado. Pero antes de entrar en procesos complejos de alteridad es necesario partir de lo básico e identificar, la manera como los sujetos educativos significan su realidad.

Para tal efecto es importante partir de la idea de que los hechos sociales no son dados naturalmente, son construidos y reconstruidos por los distintos sujetos que participan en ellos. Todo ser humano desde el momento de su nacimiento se inserta a una cultura social que le es transmitida por la familia. Esto no quiere decir que dicha transmisión sea absoluta y lineal, ya que como lo menciona Vania Salles (1998. p. 88), no todos los sujetos realizan sus interpretaciones según los patrones inculcados. Cada individuo hace una interpretación única de su contexto.

La ubicación espacio-temporal y económica del grupo familiar, así como la intersubjetividad y la simbolización que realizan de los espacios sociales en los que se desenvuelven les permite objetivizar y dar sentido a su realidad.

Los alumnos y maestros que laboran en las aulas de México, no quedan al margen de los procesos antes mencionados, puesto que ellos también hacen una interpretación de su entorno para poder interactuar en él, pero debido a que provienen de diferentes contextos, cada uno lo hace de manera particular, produciendo diferentes significados que posteriormente pondrán en juego en las dinámicas escolares. Si bien las construcciones de significados se realizan de forma singular en cada individuo, estos se ven influenciados por las condiciones, macrocontextuales, microcontextuales y masocontextuales. ${ }^{2}$

Por ello las investigaciones sociohistóricas no pueden partir de supuestos que consideren el hallazgo de verdades absolutas o realidades verdaderas, dado que cada individuo como parte rutinaria de su vida participa en la comprensión de sí mismo y de los demás. Durante dicho proceso produce acciones y expresiones significativas, pero al mismo tiempo debe interpretar las que otras personas hacen, así como los otros interpretan las elaboradas por él.

En este punto es clarificante la pos- tura de Thompson quien menciona "Al emprender la investigación sociohistórica, buscamos comprender y explicar una serie de fenómenos que, de cierta manera y hasta cierto punto, son comprendidos ya por los individuos que forman parte del mundo sociohistórico, buscamos en resumen, reinterpretar un campo preinterpretado". (Thompson, 1990: 35) 
Pero las interpretaciones a las que se puedan llegar como investigador, no deben colocarse en orden jerárquico frente a las realizadas por las personas que interactúan en el campo de estudio, puesto que son una construcción más de un significado posible, en otras palabras, el mundo social es siempre pre-interpretado, lo que inevitablemente conduce a un conflicto de interpretaciones.

Como se mencionó con anterioridad las interpretaciones de los individuos, se ven atravesadas por las condiciones sociohistóricas, económicas y políticas de las que forman parte. Por lo que no se pueden dejar de lado si se pretende construir nuevas maneras de mirar las formas simbólicas que los sujetos han realizado. La interpretación de las doxas (formas en como los individuos han significado e interpretado su realidad) serán la base para realizar el análisis sociohistórico y discursivo que permita reinterpretar el campo de estudio.

Dimensiones que se ponen en juego para simbolizar y significar la realidad.

La mente y la cultura humana tienen un carácter simbólico que les per- mite adaptar y crear su realidad en función de las representaciones simbólicas individuales y colectivas que han hecho del medio en el que interactúan. Los procesos de significación entonces se constituyen a partir de las simbolizaciones, debido a que cada individuo significa su espacio social en función de su individualidad y la colectividad en la que está inserto.

Aunque no existen dos personas que realicen procesos de simbolización y significación exactamente iguales, estos guardan una relación que les permite entenderse e interactuar, formando grupos que comparten ciertas representaciones comunes. La construcción de significados en este entendido se realiza a través de un movimiento dialéctico, en el que el contexto se inscribe en el sujeto para influirlo, pero al mismo tiempo éste se ve modificado por la psique del propio sujeto, regresando al exterior, de una forma diferente a la que fue introyectado en un inicio. Con lo anterior queda claro que los procesos de simbolización y significación son constitutivamente complejos y es imposible reducirlos a fórmulas específicas, estáticas y biunívocas, puesto que las relaciones entre significados, significantes y referentes son de carácter polivalente y polisémico. En palabras de Ricoeur, el símbolo es "una expresión de doble o múltiple sentido cuya textura semántica es correlativa del trabajo de interpretación que hace explícito su segundo sentido o sus sentidos múltiples" (Ricoeur, 1999: 5). Inevitablemente el sujeto se circunscribe dentro de un espacio social, físico y temporal en el que actúa y captura experiencias, constituyendo así su realidad; estas captaciones para ser asimiladas y utilizadas por el sujeto dentro de su espacio vital, se condensan en signos y símbolos, utilizando diferentes modos de hacerlo, ya sea a través de sonidos, imágenes, palabras, gestos y movimientos que al ser dotados de un mensaje que pretende expresar un sentido adquieren realidad social. 
El símbolo podrá desaparecer como expresión, pero el sentido quedará estructurando la subjetividad e intersubjetividad del espacio social y de sus estrategias de sobrevivencia institucional.

Así, que si se pretende comprender la forma cómo un sujeto particular lleva a cabo los procesos de construcción de significados, es indispensable conocer en primera instancia la manera en cómo simboliza ${ }^{3}$ su entorno, en este entendido es clarificante la explicación que retoma Pérez Gómez, quien basado en autores como Peirce, Goodman y Gardner, nos presenta tres dimensiones fundamentales que él considera son parte importante de la capacidad de simbolización: sintaxis, semántica y pragmática.

La primera de ellas a la que también denomina gramática, hace referencia a la estructura interna del lenguaje como código que responde a ciertas reglas de ordenación del propio sistema simbólico, esta dimensión es asumida por los sujetos en diferentes grados (según el contexto en el que se encuentre inscrito el individuo), por lo que es considerada como "la primera frontera para permitir la comunicación", debido a que cada grupo social según sus necesidades ocupa en cierta medida la sintaxis, es decir dos sujetos pueden compartir el mismo código, pero la forma en como lo ordenan al momento de utilizarlo puede ser el aspecto determinante entre entender el sentido del mensaje o quedar fuera de la acción comunicativa. (Pérez, 998: 2 5)

La semántica por su parte, relaciona el entorno con los significados, como menciona Ricoeur, ésta puede ser entendida como la "teoría que relaciona la constitución interna o inherente del significado con la in- tención externa o trascendental del la referencia". En esta dimensión, la ubicación contextual adquiere un papel más importante que la simple transmisión de reglas para la utilización de determinado lenguaje, pues entran en juego formas de asimilar la realidad, construidas por la colectividad a través del tiempo y que de alguna manera les permite compartir símbolos y significaciones comunes para su entendimiento, lo que podría significar una fractura en la comunicación entre dos personas que compartan el mismo lenguaje pero diferentes referentes. (Ricoeur,1995: 36).

La dimensión pragmática, se mueve hacia el plano de la individualidad de los sujetos que participan en el acto comunicativo, ya que hace referencia a las intencionalidades que van implícitas en las informaciones trasmitidas durante los procesos comunicativos. 
En este punto la inter- subjetividad se hace presente debido a que no sólo se ponen en juego los signos o referentes de los propios sujetos, sino que se avanza hacia las reacciones que éstos producen en las personas, locutor e interlocutor. Si bien es necesario dividir estas tres dimensiones para su estudio, esto no implica que se presenten por separado en las dinámicas cotidianas de los sujetos. Ya que el acto comunicativo como tal, no puede ser considerado así, si carece de una de las dimensiones antes descritas. (Pérez, 1998:2 9)

Con lo anterior se puede deducir que, las competencias simbólicas no pertenecen a características innatas de un grupo o clase social en específico, puesto que toda persona realiza simbolizaciones y significaciones de los escenario sociales en los que interactúa, lo que varía y constituye la diversidad, son: los mecanismos sintácticos, los esquemas semánticos y las intenciones y expectativas pragmáticas que han construido durante su interrelación con el contexto. La complejidad de las estructuras sociales de la actualidad ha hecho que personas que no comparten los mismos referentes y las mismas estructuras para significar y dar sentido a su realidad interactúen en dinámicas de desigualdad, donde las simbolizaciones y significaciones así como la manera de hacerlas, adquieren un estatus heredado por el grupo social que las produce.

El macrocontexto y sus implicaciones en las significaciones de los sujetos.

Las condiciones políticas y económicas que enmarcan a la sociedad posmoderna, juegan un papel muy importante en las significaciones que el individuo realiza y los lugares en la escala social en que éstas lo colocan. En palabras de Pérez Gómez "es imprescindible detenerse en el análisis de las peculiaridades que definen la condición posmoderna y que en definitiva condicionan la emergencia, difusión y cambio de la red de significados que componen la cultura social", la política, la economía e incluso los medios de comunicación forman parte de las cuestiones que en la actualidad influyen en las representaciones que los sujetos hacen de su espacio social, al complicarse el tipo de relaciones sociales, también se complica la estructuración de los significados, producto de esas interrelaciones. (Pérez, 998:79)

En el aspecto económico las políticas de libre mercado como estructura reguladora de la producción han propiciado la creación de un homo economicus. Que como afirma Wallerstein "busca la acumulación del capital como ley, quienes siguen esa regla crean las condiciones, mientras que los otros se ven obligados a ajustarse o a sufrir las consecuencias". La discriminación y exclusión aparecen entonces como efectos colaterales que sólo padecerán aquellos que no se encuentren preparados para enfrentar los retos que la nueva organización social les demande. (Wellerstein, 1983:7) 
Pero la preparación que se exige lejos de darse en un clima de intercambio, diálogo y construcción compartida, hace que los intercambios de significados entren en dinámicas de comercialización, estructurando un mercado lingüístico que asigna leyes de formación de precios. Al igual que el mercado económico, el lingüístico se ve sumergido en luchas de poder, y violencia simbólica, puesto que los sujetos que produzcan su capital lingüístico dentro la cultura hegemónica tendrá la posibilidad de participar en intercambios más justos, en comparación con aquellos que constituyan su capital en espacios menos favorecidos, debido a que estos últimos, al no dominar el campo tendrán menos posibilidades de hacerlo funcionar en su beneficio (Bourdieu, 984: 46). Implícitamente la primacía de normas culturales con alta estima, genera como efecto perverso la erradicación de las normas culturales a las que considere como rivales.

En este punto es fácil caer en la falsa ilusión de considerar a las condiciones macrocontextuales como inamovibles, pero no se debe perder de vista que son al igual que el resto de los hechos socia- les, creaciones que constantemente se reelaboran y ajustan, producto de la interacción de los sujetos que constituyen el conjunto de instituciones que integran el sistema económico global.

Sin embargo, es pertinente puntualizar que los cambios experimentados en el ámbito económico, no se dan en aislado, sino que repercuten directamente en sistemas como el político, debido a que los intercambios económicos a nivel global hacen que las decisiones políticas dejen de tener un carácter local y dirijan la toma de decisiones a esferas más globales. Al mismo tiempo se privilegia un pensamiento único que socava las diferencias y disuelve las identidades descontextualizándolas, borrando la memoria y las tradiciones que permitían a los sujetos hacer construcciones para identificarse y reconocerse en su entorno.

El conflicto manejado desde posturas democráticas, el discurso y el diálogo que posibilita la construcción y reconstrucción de las opiniones e intereses, se ven sustituidos por la seducción del individuo que deja campo fértil para una expropiación política reduciendo a ésta a la sim- ple acumulación de votos, que se obtienen mediante la manipulación publicitaria, permitiendo como lo plantea Pérez Gómez: "satisfacer a los más poderosos y mejor organizados sus necesidades particulares". Pero haciendo parecer a las posturas políticas impuestas como propias o compartidas. Queda claro entonces que la conquista de la opinión pública se encuentra mediatizada, lo que hace que me dirija al siguiente aspecto 
macrocontextual que considero relevante en la producción de significaciones, los medios masivos de comunicación. (Pérez, 1998: 99)

La forma rápida en que se distribuye la información en la aldea global ha hecho que se produzcan modificaciones sustanciales en las representaciones que las personas hacen de su realidad. Los intereses se modifican así como el carácter de los símbolos y la naturaleza de los espacios locales. Por lo que inevitablemente los sujetos sufren una fractura en la forma que tienen de significar su entorno, ya que el complejo mundo que se abre ante sus ojos no puede ser aprehendido con los mecanismos que utilizaban en el pasado. Lo anterior no quiere decir que las personas dejen de significar su medio social, cuando las herramientas que tenían para hacerlo ya no son funcionales en el contexto, sino más bien que las aprehensiones que se realizan tienen un vacío conceptual y estructural que los hace presa fácil de la seducción y manipulación publicitaria que los bombardea día a día, es decir la envoltura comienza a tener más importancia que el propio contenido. Por tanto no se trata siquiera de desenmascarar "ideologías falsas" sino de identificar el vacío semántico e ideológico que trata de llenarse con saturación de palabras "sinsentido".

Ante todo lo descrito anteriormente es pertinente plantearse la pregunta ¿Qué papel juegan los docentes dentro de dichos sucesos? Recordemos que si bien no hay formulas mágicas, sí existen acciones que contribuyen a la toma de decisiones más conscientes, es por ello que considero que los docentes como profesionales, deben asumir el control de su propia formación y desarrollar una práctica más reflexiva en la que, como lo menciona Pérez Gómez, "emerja un sujeto capaz de convertirse en agente consciente de interpretación, creación y transformación. Para convertirse en el sujeto crítico de sus propias elaboraciones y conductas" (Pérez, 998: 259) .

Es indispensable que el maestro se asuma a sí mismo como un intelectual que es capaz de participar en la elaboración de objetivos y condiciones de enseñanza que se relacionen directamente con los espacios reales en los cuales interactúa. Recordando que los aspectos que funcionan en determinados espacios sociales, no necesariamente lo harán en otros, porque las aulas, en palabras de Erickson, son lugares donde también existe una estructura social dentro de la cual se inserta la vida en el aula. (Erickson, 989:220) 
Si bien, como ya mencioné, no se pueden dejar de lado las cuestiones políticas y económicas que atraviesan inevitablemente la formación del profesorado y la vida en los salones de clases, debido a que los espacios sociales no son lugares neutros, desde el momento en que todos los su- jetos toman posturas frente a su espacio social. No quiere decir que las personas deban apropiar lo que el contexto les brinda, sin posibilidad de cuestionar, proponer y transformar. Lo que sí queda claro es que si los mecanismos de significación son débiles, las construcciones estarán direccionadas por la seducción, si son críticas y reflexivas tendrán, necesariamente, una construcción basada en la argumentación. Así que si "los profesores han de educar a los estudiantes para ser ciudadanos activos y críticos, deberían convertirse ellos mismos en intelectuales trasformativos." (Giroux, 990: 77)

Pero ¿qué significa ser intelectuales transformativos?, Giroux, clara- mente menciona que no significa establecer un currículo, sino llevarlo a la práctica, desprenderse de las propias sedimentaciones para estructurar conjuntamente con los alumnos una cultura académica, que involucre y cuestione tanto la cultura experiencial de los actores educativos como la cultura crítica del currículo, para poder realizar transformaciones.

La sociedad actual experimenta cambios rápidos, que han transformado los sistemas económicos y políticos, haciendo que los intereses de las personas así como su forma de significarlos cambien de manera radical. La educación no puede quedar al margen de estas trasformaciones, por lo que, las escuelas dentro de la posmodernidad deben abrir espacios que les permitan a los alumnos organizar y estructurar el cúmulo de información que reciben a diario. La saturación de información sin las herramientas necesarias para procesarla propicia un clima de desinformación, que crea confusión y pérdida del sentido semántico de los intercambios simbólicos. Produciendo efectos colaterales sintomáticos que pretenden ser solucionados, como si fueran el problema mismo, ocultando así la verdadera problemática que aqueja a la sociedad posmoderna.

El maestro por tanto debe desarrollar las herramientas necesarias que le permitan, abandonar las posturas reproductoras y socializadoras de la escuela, para retomar una postura más académica, en donde los conocimientos no sólo sirvan al alumno para contestar exámenes y obtener éxito en ambientes artificiales. Es preciso asumir la responsabilidad de potenciar los espacios realmente formativos, tanto para alumnos como maestros, abandonando tabúes y sedimentaciones que encasillan a la docencia y a la escuela misma como meros reproductores. 
Si bien el camino no es fácil, las nuevas posturas son incorporadas dentro de las aulas en un clima de divergencia y contradicción que en suma otorgan la dinámica que toda institución debe poseer si se pretende mantener con vida, la presión por parte del sistema económico para generar personas reproductoras de la ideología liberal dominante, así como, los espacios coyunturales que pugnan por una transformación permiten al docente encontrar sentido en su profesión. Enriquecedora es en este sentido la postura de Argullol retomada por Pérez Gómez cuando menciona "Lo peor que podría ocurrirnos sería aceptar una sociedad, y una vida, sin deseo.

El deseo siempre implica una tensión entre el espacio que habitas y un espacio eventual que se proyecta en tu mente y en tu sensibilidad" (Pérez, 1998: 21 ).

\section{NOTAS}

Para Vania Salles, la familia no solo actúa como reproductora social, sino como productora debido a que existen variables hermenéuticas que permiten la apropiación o el rechazo de prácticas y costumbres establecidas socialmente.

2 El macrocontexto es la estructura superior política, social y económica que determina las características dominantes de las relaciones sociales. Por su parte el microcontexto es el escenario vital concreto que rodea la vida del individuo durante todo su desarrollo (familia, aula). Por último el mesocontexto responde al escenario intermedio con el que el individuo humano se pone en contacto aunque no forma parte de su marco existencial concreto (ciudad, sistema político.)

3 Ya que si bien los símbolos también son signos, estos se distinguen de los últimos, por tener un sentido más amplio y menos concreto, alejándose en su expresión de la cosa representada y siendo exclusivos de los seres humanos, que son los que los dotan de significado dentro de una realidad. 


\section{FUENTES DE CONSULTA}

- BOURDIEU, Pierre. (1984). Sociología y cultura. México: Grijalbo.

- ERICkSON, Frederick. (1989). La enseñanza de la Investigación II . Bar- celona: Paidós-MEC.

- GIROUX, Henry A. (1990). Los profesores como intelectuales: Hacia una pedagogía crítica del aprendizaje. España: Paidós.

- PÉREZ, Gómez Ángel. (1998). La cultura escolar en la sociedad Neoliberal. Madrid: Morata

- RICOEUR, Paul. (1999). Freud: una interpretación de la cultura. México: Siglo XXI

- RICOEUR, Paul. (1995). Teoría de la interpretación. Discurso y excedente de sentido. Mexico: siglo XXI y Universidad Iberoamericana.

- SALLES, Vania. (1998) .Vida familiar y cultura contemporánea.

México: Conaculta.

- THOMPSON, John B. (1993) Ideología y cultura moderna. Teoría crítica social en la era de la comunicación de masas. México: Universidad Metropolitana.

- WELLERSTEIN, Immanuel. (1988). El capitalismo histórico. México: Siglo $X X I$. 